Word Count 4500

\title{
In-vitro investigation of the hemodynamic responses of the cerebral, coronary and renal circulations with a rotary blood pump installed in the descending aorta
}

\author{
M. A. Rezaienia ${ }^{a}$, G. M. Paul ${ }^{\text {a }}$ E. J. Avital ${ }^{\mathrm{a}}$, S. Mozafaria ${ }^{\mathrm{a}}$, M. Rothman ${ }^{\mathrm{b}}$, T. Korakianitis ${ }^{\mathrm{c}, *}$ \\ ${ }^{a}$ School of Engineering and Materials Science, Queen Mary University of London, London, E1 4NS, UK \\ ${ }^{b}$ Department of Cardiology, London Chest Hospital, Barts and the London NHS Trust, London, E2 9JX, UK \\ ${ }^{c}$ Parks College of Engineering, Aviation and Technology, Saint Louis University, St. Louis, Missouri 63103, USA
}

\begin{abstract}
This study investigates the hemodynamic responses of the cardiovascular system when a rotary blood pump is operating in the descending aorta, with a focus on the cerebral, coronary and renal autoregulation, using our in-house cardiovascular emulator. Several improvements have been made from our previous studies. A novel coronary system was developed to replicate the native coronary perfusion. Three pinch valves actuated by stepper motors were used to simulate the regional autoregulation systems of the native cerebral, coronary and renal circulations. A rotary pump was installed in the descending aorta, in series with the heart, and the hemodynamic responses of the cardiovascular system were investigated with a focus on cerebral, coronary and renal circulation over a wide range of pump rotor speeds. Experiments were performed twice, once with the autoregulation systems active and once with the autoregulation systems inactive, to reflect that there will be some impairment of autoregulatory systems in a patient with heart failure. It was shown that by increasing the rotor speed to $3000 \mathrm{rpm}$, the cardiac output was improved from 2.9 to $4.1 \mathrm{~L} / \mathrm{min}$ as a result of an afterload reduction induced by the pressure drop upstream of the pump. The magnitudes of changes in perfusion in the cerebral, coronary and renal circulations were recorded with regional autoregulation systems active and inactive.
\end{abstract}

Keywords: Cardiovascular simulator, Blood pump, MCS, RBP, VAD

\footnotetext{
*Dean of Parks College of Engineering, Aviation and Technology, Saint Louis University, St. Louis, Missouri 63103, USA.

Email address: Email forward for life korakianitis@alum.mit.edu (T. Korakianitis)
} 


\section{Nomenclature}

\section{Subscripts}

$\begin{array}{ll}\text { ao } & \text { aortic } \\ \text { dia } & \text { diastolic } \\ \text { mean } & \text { mean } \\ \text { pp } & \text { pulse pressure } \\ \text { sys } & \text { systolic }\end{array}$

Abbreviations and Acronyms

AoP aortic pressure

AV aortic valve

C compliance

CHF congestive heart failure

$\mathrm{CeF} \quad$ cerebral flow rate

$\mathrm{CeP} \quad$ cerebral pressure

$\mathrm{CO} \quad$ cardiac output

CoF coronary flow rate

CoP coronary pressure

CVR cerebrovascular resistance

DA descending aorta

F flow-meter

LA left atrium

LV left ventricle

LM linear motor

LVP left ventricular pressure

MCS mechanical circulatory support

MV mitral valve

$\mathrm{P} \quad$ pressure

PV pulmonic valve

Q flow rate

RBP rotary blood pump

$\mathrm{RA}$ right atrium

ReP renal pressure

ReF renal flow rate 
RV right ventricle

RVP right ventricle pressure

SCVL simulator of cardiovascular loops

$\mathrm{SyF} \quad$ systemic flow

TV tricuspid valve

\section{Introduction}

The number of deaths caused by Heart Failure (HF) has decreased during the past decade in developed countries, yet HF is still the leading cause of deaths in the world. In the United States, in a ten year period from 2001 to 2011, death rates attributable to HF and the actual number of HF deaths declined by $30.8 \%$ and $15.5 \%$ per year respectively, yet in $2011 \mathrm{HF}$ still accounted for $31.3 \%$ of all deaths [1]. Despite all available therapies to this problem, heart transplant is the main option for end-stage HF patients. However, with a limited number of heart donors available annually (2500 for USA, 1400 Europe and 300 other countries $[2,3]$ ) the rate of mortality remains very high for patients on and off the waiting list.

As a result, Rotary Blood Pumps (RBP)have become vital for end-stage HF patients as a bridge to transplantation or destination therapy $[4,5]$. One of the challenges with the traditional RBPs is their highly invasive implantation procedure which makes many elderly and ill patients ineligible for the surgery. This has encouraged many researchers to investigate new approaches with potential for minimally invasive surgery $[6,7]$.

Transaortic or in-series miniature RBPs, distant from the heart, are one minimally invasive solution [811]. The implantation of a RBP in the Descending Aorta (DA), in series with the heart, has been of growing interest among various groups $[6,8,12-15]$. It was reported that the insertion of an RBP device in the descending aorta leads to an improved cardiac output, yet there is a question related to the impact of the pressure drop generated upstream of the pump on blood perfusion in the upper extremities, particularly the brain and heart $[6,12,13,16]$. In addition, there is a concern associated with the effect of the pressure rise downstream of the pump on lower extremities, particularly the kidneys [17].

The regional autoregulation systems, which maintain a constant flow rate to vital organs during changing local perfusion pressure, are present in many organs of the native cardiovascular system, however thet are most pronounced in the heart, brain and kidneys [18]. The cerebral autoregulation is a vital homeostatic mechanism to maintain the blood supply to the brain in the event of changing perfusion pressure. For a healthy person, the cerebral circulation is autoregulated within wide limits of mean aortic pressure from 60 to $120 \mathrm{mmHg}[19,20]$. The coronary circulation maintains the blood supply to the heart and is autoregulated within 45 to $130 \mathrm{mmHg}$ in a healthy person [21]. The renal autoregulation has been extensively investigated 
in prior studies $[22,23]$. In a native human body the renal blood supply is relatively constant when the mean arterial pressure varies between 90 and $180 \mathrm{mmHg}$ [22]. It must be noted that various pathological conditions, including hypertension, hypotension and a change in arterial $\mathrm{CO}_{2}$ level can alter the upper and lower limits of the autoregulated region [24].

The aim of this study is to investigate the hemodynamic responses of the cardiovascular system when a rotary pump is operating in the descending aorta with a focus on the cerebral, coronary and renal circulation. Since the regional autoregulation can be impaired in heart failure patients, the hemodynamic response is investigated with intact and impaired regional autoregulation. An expected outcome is to estimate what level of support is feasible while avoiding the previously mentioned risk of drops in perfusion to the coronary and cerebral circulations.

The objectives of this study are met using our in-house multi-chamber Simulator of Cardio-Vascular Loops (SCVL). Cardiovascular simulators offer a more controlled and inexpensive platform to evaluate the performance of existing blood-contacting devices as well as new medical concepts, prior to in-vivo studies. In recent years, much progress has been made in the design and development of cardiovascular simulators with close similarity to a native system for research and training [25-28].

In the present study, several improvements have been made from our previous studies $[6,12,13,29]$. The coronary perfusion mechanism which causes the heart to be perfused only during diastole was implemented using a solenoid valve. In addition, the coronary and renal autoregulation circulations, similar to the cerebral autoregulation mechanism presented in our previous study [29], were integrated into the SCVL system, with autoregulation limits determined from the clinical data.

\section{Methodology}

The native cardiovascular system of an adult human was emulated using our in-house SCVL system, as shown in the schematic digram of Figure 1.

Four elastic rubber chambers were used to model the native heart chambers. The left and right ventricles (LV and RV) had a volume of $100 \mathrm{~mL}$ and the left and right atrium (LA and RA) had a volume of $50 \mathrm{~mL}$. Four linear motors (P01-37×120 from LinMot, Spreitenbach, Switzerland) were employed to simulate the contraction and dilation of the ventricle and atrium chambers. Two trajectory time-varying functions extracted from the real time left ventricle and left atrium volume, as described in our previous study [29], were employed to actuate the four linear motors. Figure 2 shows the simultaneous graphs of trajectory time-varying functions of the ventricles and atria for an intact heart. Each function can be scaled up or down in order to replicate various physiological and pathological conditions.

Four prosthetic heart valves (Medtronic, Minneapolis, Minnesota, USA) modelling the aortic ,mitral, pulmonary and tricuspid valves were used to ensure unidirectional flow in the vicinity of each chamber. 


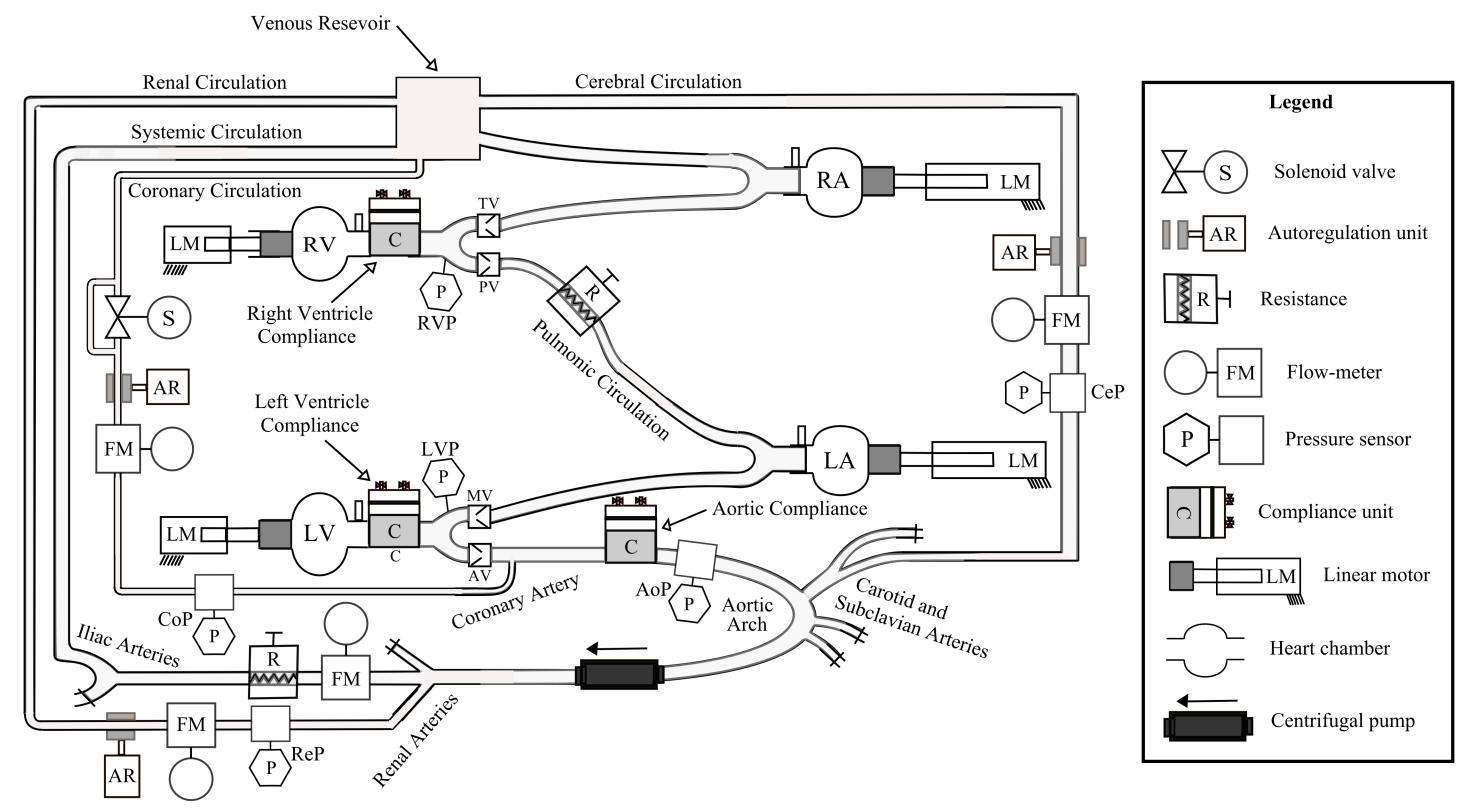

Figure 1: Schematic diagram of the SCVL system with the coronary, cerebral and renal autoregulation units and an RBP device in the descending aorta.

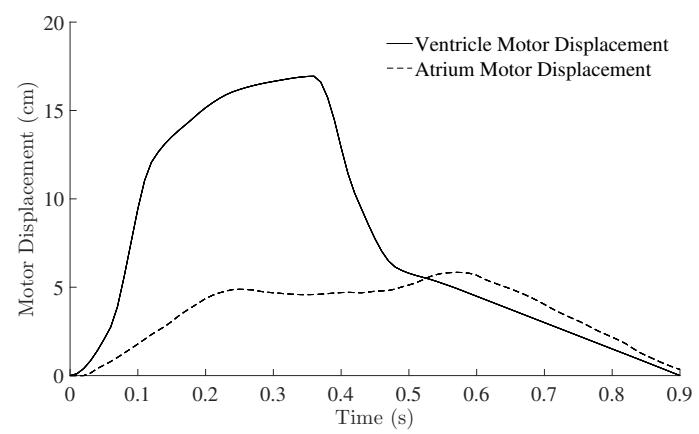

Figure 2: The predefined time-varying trajectory functions of the ventricles and atria, adopted from the study conducted by Rezaienia et al. [29]

61 The systemic and pulmonary circulations are replicated using $24 \mathrm{~mm}$ diameter rubber tubing, while smaller arteries are replicated using $12 \mathrm{~mm}$ diameter rubber tubing. A blood analog solution comprising of $65 \mathrm{wt} \%$ water and 35 wt\% glycerol was used as the working fluid, as in the study conducted by Pantalos et al. [27].

Five pressure transducers (PMP 5074, accuracy \pm 0.1 FS BSL) from General Electric, Billerica, MA, USA were used to simultaneously measure the Left Ventricle Pressure (LVP), Aortic Pressure (AoP), Right was defined as equal to the AoP.

A number of Hoffman clips were used to manually control the systemic and pulmonary resistance level to allow tuning of the SCVL system. Three electromagnetic flow-meters (SITRANS F M MAG 1100 F, accuracy 


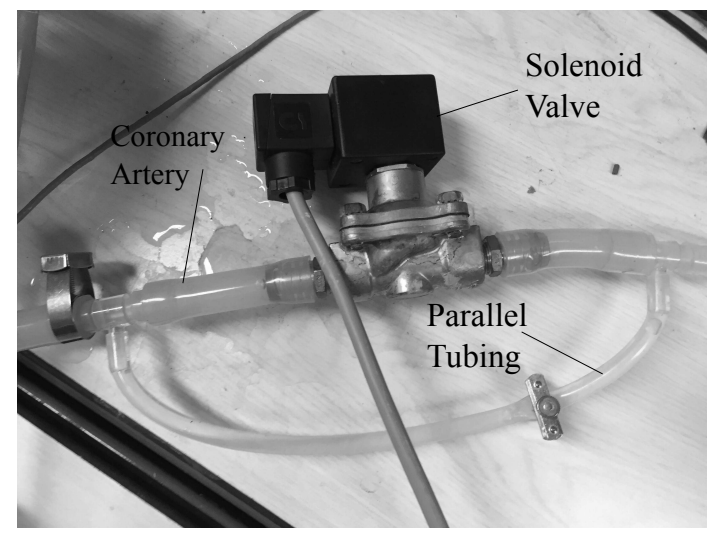

Figure 3: Photograph of the coronary perfusion mechanism incorporating a parallel configuration of a solenoid valve and tubing.

$0.4 \% \pm 1.0 \mathrm{~mm} / \mathrm{s}$ ) from Siemens, Munich, Germany) were employed to measure the Cerebral Flow (CeF), Coronary Flow (CoF) and Renal Flow (ReF), respectively and an ultrasonic flow-meter (Cynergy UF Flow, C3, accuracy 3\% of reading) (Cynergy UF Flow, C3) was used to measure the Systemic Flow (SyF). The sum of these flows gives the Cardiac Output (CO). The vascular distensibility of the systemic and pulmonary circulations was replicated using a number of compliance units developed in our previous experiment [29]. The compliance level for each unit can be adjusted to match the vascular distensibilty of a native system for various pathological conditions.

A parallel configuration of a solenoid valve and narrow tubing was used to model the coronary perfusion mechanism, as shown in Figure 3. In a native system, coronary blood flow occurs predominantly during diastolic phase when the heart muscles are relaxed and thereby the lumen of the coronary arterioles are fully open [30]. The solenoid valve was programmed to be closed during systole and remain open during diastole. This allows a small portion of the coronary flow to bypass the valve via the tubing during the systolic phase, but the larger portion of the flow occurs via the solenoid valve during the diastolic phase.

Three autoregulation units were attached to the carotid, coronary and renal arteries, as shown in Figure 1. Each unit takes the form of a pinch valve driven by a stepper motor, as shown in Figure 4, and applies dilation and constriction to the cerebral, coronary, and renal arteries as occurs in a native system. The flow is adjusted to the autoregulated level when the pressure is within the regulated region, using the appropriate flow-meter as feedback for the control system. Outside of the autoregulated region, the pinch valve is at maximum or minimum dilation depending on whether the pressure is below or above the autoregulated region respectively. Clinical data for each autoregulation unit's pressure/flow profile was taken from suitable in-vivo studies $[19,21,31]$. 


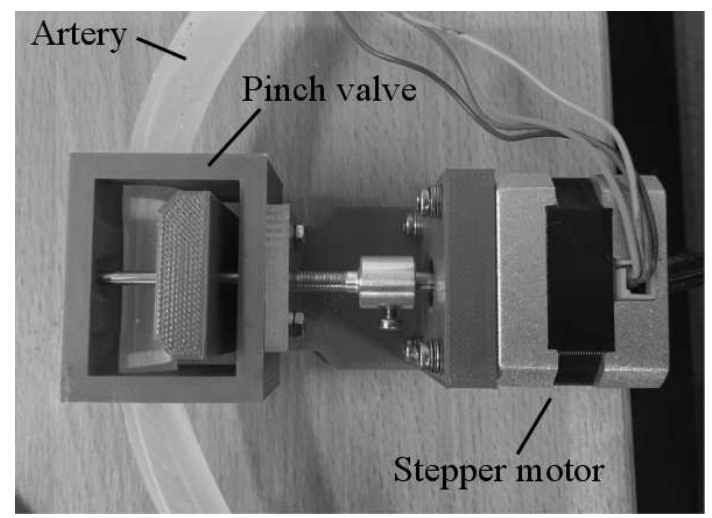

Figure 4: Photograph of the autoregulation unit using the stepper motor.

\section{Results}

\subsection{SCVL Performance}

A healthy condition and a HF condition were replicated in order to evaluate the efficacy of SCVL system. For the healthy condition, the four linear motors were operating in full scale according to the trajectory functions shown previously in Figure 2. Modelling of the HF condition is more difficult, since in this condition the heart's chambers deform, the LV dilates and mechanism of contraction changes. For this study, the HF condition was reproduced by decreasing the minimum displacement of the LV linear motor, replicating an increased diastolic LV volume, and decreasing the maximum displacement of the LV linear motor, replicating a reduced LV pumping ability. The LV dilation was modeled by integrating a compliance unit upstream of the aortic valve, as shown in Figure 1, and increasing its compliance. In addition, the vascular distensibility was decreased by reducing the compliance level to simulate a stiffer vascular system and the systemic resistance was increased slightly.

The SCVL was tuned so that the pressure and flow rate in healthy and HF conditions matched the corresponding clinical data extracted from suitable clinical publications [30, 32-34].

Figures 5(a,b) show the experimental AoP, LVP and RVP for the healthy and HF conditions respectively. The measured AoP, LVP and RVP waveforms for the healthy condition are 120/82, 120/5 and 30/5 mmHg respectively. The measured AoP, LVP and RVP waveforms for the HF condition are 107/74, 107/25 and $48 / 25 \mathrm{mmHg}$ respectively. It is evident that the dicrotic notch (incisura), occurring due to a slight backflow into the native left ventricle, has been reflected clearly on the descending limb of the simulated AoP waveform. The small pressure bump appearing just before the ascending limb of the LVP waveform is due to the systolic contraction of the atrium as occurs in the native system [30].

The $\mathrm{CO}$ for the healthy and $\mathrm{HF}$ conditions were recorded as $5.1 \mathrm{~L} /$ min and $2.9 \mathrm{~L} /$ min and the $\mathrm{AoP}_{\text {mean }}$ for the healthy and HF condition are 95 and $85 \mathrm{mmHg}$, respectively. The SCVL correctly simulates the main physiological features of the pressure waveforms in good agreement with clinical data [30, 32-34]. A 

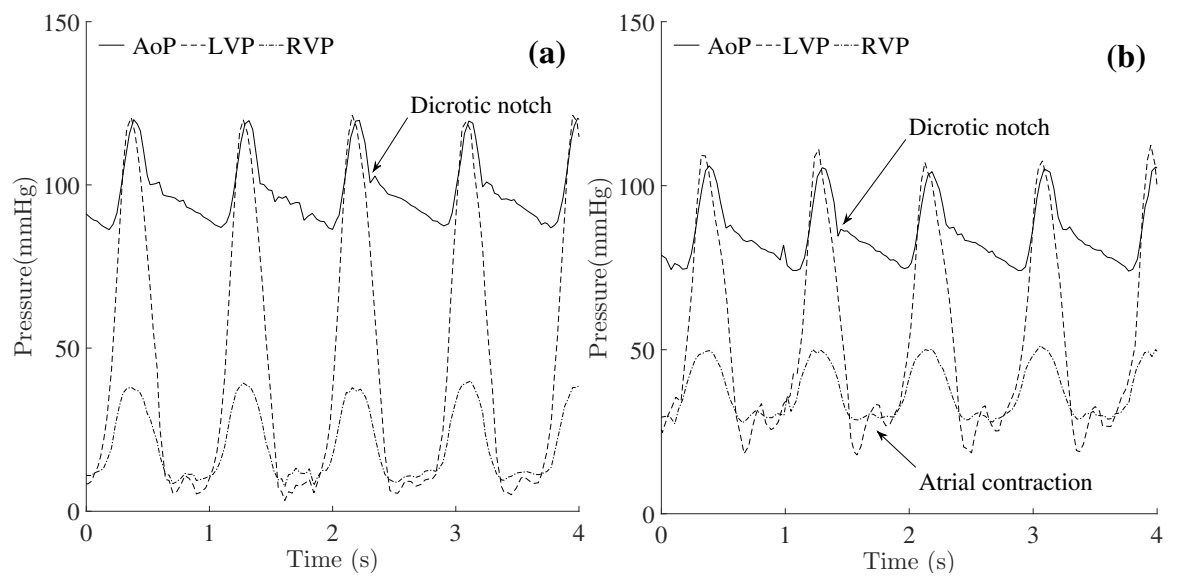

Figure 5: (a) The experimental AoP, LVP and RVP waveforms for the healthy condition. (b) The experimental AoP, LVP and RVP waveforms for the heart failure condition.

smooth waveform is obtained without any signal filtering because the valve closing pressure spikes often present in cardiovascular simulators [35] are dampened by the compliance units.

\subsection{Coronary Perfusion Mechanism}

Figures 6(a,b) show AoP and CoF with the SCVL operating in the healthy condition. During the systolic phase CoF drops to $50 \mathrm{ml} / \mathrm{min}$ and during the diastolic phase it rises to a maximum of $400 \mathrm{ml} / \mathrm{min}$. This is in agreement with the observed coronary perfusion in a native system [21,30].

\subsection{Autoregulation Units}

The performance of the cerebral, coronary and renal autoregulation units are evaluated by applying a number of stepwise pressure reductions in the systemic artery and subsequently recording the steady state $\mathrm{CeF}_{\text {mean }}, \mathrm{CoF}_{\text {mean }}$ and $\mathrm{ReF}_{\text {mean }}$. For this study, the performance of only the cerebral autoregulation unit

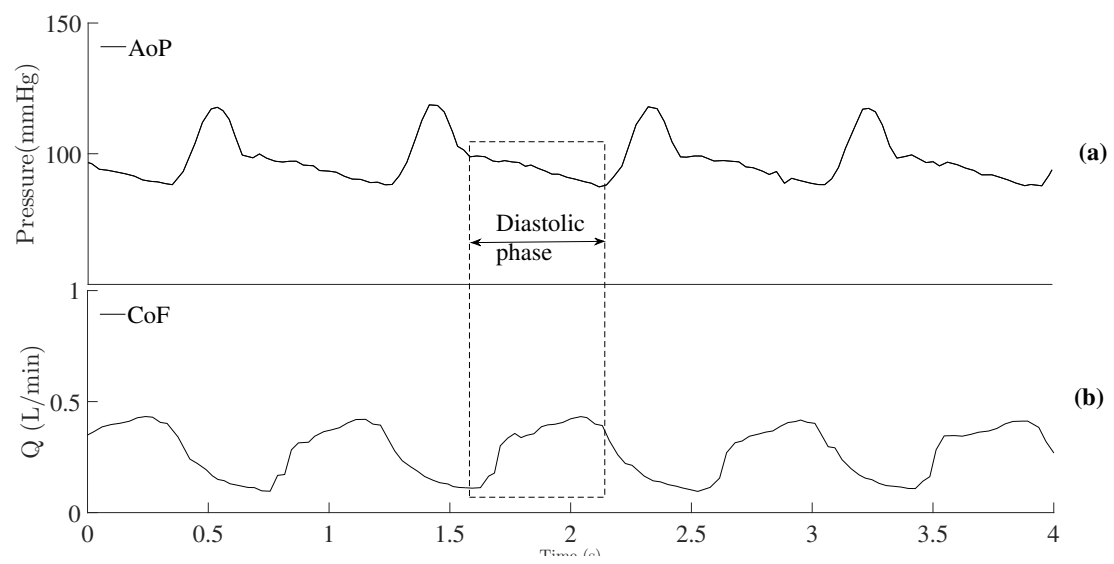

Figure 6: (a) The experimental AoP waveforms for the healthy condition. (b) The experimental CoF waveform for the healthy condition. 
(a)

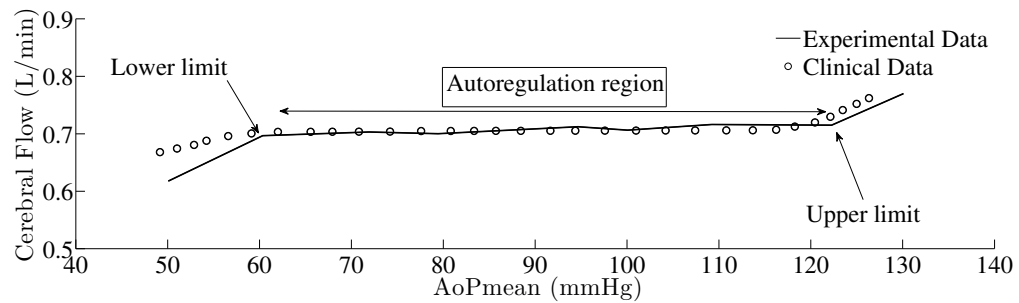

(b)

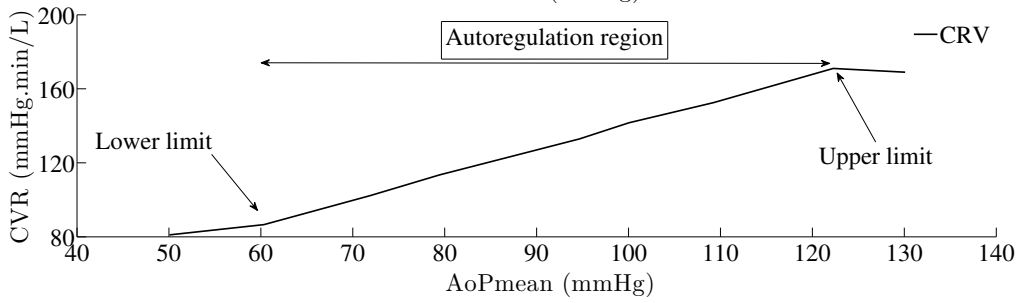

Figure 7: The performance of the cerebral autoregulation unit from 60 to $120 \mathrm{mmHg}$, adopted from the study conducted by Rezaienia et al. [29]. (a) Cerebral flow in the SCVL compared with clinical data [24] and (b) the CVR from the same experiment.

is presented on the basis that the other two units have the same functionality but different autoregulated ranges.

Initially, the $\mathrm{AoP}_{\text {mean }}$ was set at $125 \mathrm{mmHg}$. In systemic resistance incremental reductions were introduced into the SCVL system. For each step the $\mathrm{AoP}_{\text {mean }}$ and $\mathrm{CeF}_{\text {mean }}$ were recorded after ten seconds to ensure that the transient flow was settled. The step period on the stepper motor was adjusted to ensure the autoregulation response is typically around five seconds as observed in the clinical study [36], although this varies slightly depending on the magnitude of the pressure change.

Figure 7 shows the cerebral autoregulation pressure-flow curve and the corresponding CerebroVascular Resistance (CVR). As shown in Figure 7(a), the autoregulated $\mathrm{CeF}_{\text {mean }}$ is set at $0.71 \mathrm{~L} / \mathrm{min}$, as measured in the clinical study conducted by Ford et al. [37] for a normotensive human. It is evident that within the autoregulated region, 60-120 mmHg, the cerebral flow remains unchanged. However, outside the autoregulated region the $\mathrm{CeF}_{\text {mean }}$ level is proportional to the $\mathrm{AoP}_{\text {mean }}$ level, with the autoregulated artery at a maximum dilation or a maximum contraction. Figure $7(\mathrm{~b})$ shows that as the $\mathrm{AoP}_{\text {mean }}$ level gradually decreases, the CVR decreases to ensure that the cerebral flow remains unchanged within the autoregulated region. 


\subsection{Integration of a Rotary Pump in the Descending Aorta}

A HF condition was reproduced in which the $\mathrm{AoP}_{\text {mean }}$ and the $\mathrm{CO}$ are $85 \mathrm{mmHg}$ and $2.9 \mathrm{~L} / \mathrm{min} \mathrm{re}-$ spectively. A rotary pump simulating a RBP device was implemented in the descending aorta above the renal arteries, in series with the heart, as shown in Figure 1. The pump is an in-house bench-top centrifugal pump with the hydrodynamic characteristics of $70 \mathrm{mmHg}$ against $5 \mathrm{~L} / \mathrm{min}$ at $3000 \mathrm{rpm}$. Five experiments were conducted in which the hemodynamic responses of pressures AoP, LVP, CoP, CeP and ReP as well as flow rates $\mathrm{SyF}, \mathrm{CeF}, \mathrm{CoF}, \mathrm{ReF}$ and $\mathrm{CO}$ were recorded with the pump operating over rotor speeds from 0 to $4000 \mathrm{rpm}$ in increments of $1000 \mathrm{rpm}$. This was repeated with the regional autoregulation systems active and inactive. The results are summarized in Table 1 and Table 2.

There is an improvement in $\mathrm{CO}$ whether or not the regional autoregulation system is active. At $3000 \mathrm{rpm}$ the CO has increased by $42 \%$. Since there is a large resistance downstream of the pump, the pressure drop upstream of the pump in the aortic arch (see CeP and CoP) is relatively small (-13\% at $3000 \mathrm{rpm}$ with autoregulation inactive) compared to the pressure rise downstream of the pump (see ReP) which is far larger $(+106 \%$ at $3000 \mathrm{rpm}$ with autoregulation inactive).

Figure 8 shows the $\mathrm{ReP}$ and $\mathrm{CeP}$ waveforms as the pump accelerated to $3000 \mathrm{rpm}$, at which point a pressure rise of $82 \mathrm{mmHg}$ is recorded across the pump. The dashed line represents the measured ReP waveform downstream of the pump and the solid line represents the CeP waveforms upstream of the pump. At $\mathrm{T}=3 \mathrm{~s}$, when the pump is switched on, the CeP gradually decreases over the course of ten seconds until $\mathrm{CeP}_{\text {mean }}$ reaches a steady level of $88 \mathrm{mmHg}$. In contrast, ReP mean is increased from $80 \mathrm{mmHg}$ for $\mathrm{HF}$ condition until it reaches the steady level of $170 \mathrm{mmHg}$. It is also shown that upon insertion of the pump, the cerebral pulse pressure $\left(\mathrm{CeP}_{\mathrm{pp}}\right)$, and renal pulse pressure $\left(\mathrm{ReP}_{\mathrm{pp}}\right)$, determined by subtracting

Table 1: SCVL Hemodynamic characteristics with active regional autoregulation systems for the healthy and HF conditions with an MCS device in the DA operating from 0 to $4000 \mathrm{rpm}$.

\begin{tabular}{|c|c|c|c|c|c|c|c|}
\hline Condition & Healthy, $0 \mathrm{rpm}$ & $\mathrm{HF}, 0 \mathrm{rpm}$ & $\mathrm{HF}, 1000 \mathrm{rpm}$ & $\mathrm{HF}, 2000 \mathrm{rpm}$ & $\mathrm{HF}, 3000 \mathrm{rpm}$ & $\mathrm{HF}, 4000 \mathrm{rpm}$ & Units \\
\hline$\Delta \mathrm{P}$ & - & - & 5 & 36 & 82 & 130 & $\mathrm{mmHg}$ \\
\hline $\mathrm{AoP}_{\text {mean }}$ & 95 & 85 & 82 & 78 & 74 & 68 & $\mathrm{mmHg}$ \\
\hline $\mathrm{AoP}_{\mathrm{sys}}$ & 116 & 107 & 104 & 101 & 98 & 95 & $\mathrm{mmHg}$ \\
\hline $\mathrm{AoP}_{\text {dia }}$ & 82 & 75 & 71 & 67 & 62 & 55 & $\mathrm{mmHg}$ \\
\hline $\mathrm{CoP}_{\text {mean }}$ & 95 & 85 & 82 & 78 & 74 & 68 & $\mathrm{mmHg}$ \\
\hline $\mathrm{CeP}_{\text {mean }}$ & 105 & 94 & 92 & 89 & 88 & 80 & $\mathrm{mmHg}$ \\
\hline $\mathrm{ReP}_{\text {mean }}$ & 90 & 80 & 97 & 125 & 170 & 220 & $\overline{\mathrm{mmHg}}$ \\
\hline $\mathrm{CeP}_{\mathrm{pp}}$ & 34 & 32 & 33 & 34 & 36 & 41 & $\mathrm{mmHg}$ \\
\hline $\mathrm{ReP}_{\mathrm{pp}}$ & 27 & 25 & 28 & 29 & 41 & 45 & $\mathrm{mmHg}$ \\
\hline $\mathrm{CeF}_{\text {mean }}$ & 0.71 & 0.71 & 0.71 & 0.71 & 0.71 & 0.70 & $\mathrm{~L} / \min$ \\
\hline $\mathrm{CoF}_{\text {mean }}$ & 0.22 & 0.22 & 0.22 & 0.22 & 0.22 & 0.21 & $\mathrm{~L} / \mathrm{min}$ \\
\hline $\mathrm{ReF}_{\text {mean }}$ & 1.21 & 1.20 & 1.19 & 1.19 & 1.21 & 1.46 & $\mathrm{~L} / \mathrm{min}$ \\
\hline $\mathrm{SyF}_{\text {mean }}$ & 2.97 & 0.77 & 0.97 & 1.13 & 1.98 & 2.25 & $\mathrm{~L} / \mathrm{min}$ \\
\hline $\mathrm{CO}$ & 5.11 & 2.90 & 3.09 & 3.25 & 4.12 & 4.62 & $\mathrm{~L} / \mathrm{min}$ \\
\hline
\end{tabular}


Table 2: SCVL Hemodynamic characteristics with inactive regional autoregulation systems for the healthy and HF conditions with an RBP device in the DA operating from 0 to $4000 \mathrm{rpm}$.

\begin{tabular}{|c|c|c|c|c|c|c|c|}
\hline Condition & Healthy, 0 rpm & $\mathrm{HF}, 0 \mathrm{rpm}$ & $\mathrm{HF}, 1000 \mathrm{rpm}$ & $\mathrm{HF}, 2000 \mathrm{rpm}$ & $\mathrm{HF}, 3000 \mathrm{rpm}$ & $\mathrm{HF}, 4000 \mathrm{rpm}$ & Units \\
\hline$\Delta \mathrm{P}$ & - & - & 5 & 36 & 82 & 130 & $\mathrm{mmHg}$ \\
\hline $\mathrm{AoP}_{\text {mean }}$ & 95 & 85 & 81 & 78 & 73 & 65 & $\mathrm{mmHg}$ \\
\hline $\mathrm{AoP}_{\mathrm{sys}}$ & 116 & 107 & 102 & 100 & 96 & 90 & $\mathrm{mmHg}$ \\
\hline $\mathrm{AoP}_{\text {dia }}$ & 82 & 75 & 71 & 65 & 59 & 47 & $\mathrm{mmHg}$ \\
\hline $\mathrm{CoP}_{\text {mean }}$ & 95 & 85 & 81 & 78 & 73 & 65 & $\mathrm{mmHg}$ \\
\hline $\mathrm{CeP}_{\text {mean }}$ & 105 & 94 & 93.5 & 90 & 85 & 75 & $\mathrm{mmHg}$ \\
\hline $\mathrm{ReP}_{\text {mean }}$ & 90 & 80 & 98.3 & 119 & 165 & 215 & $\mathrm{mmHg}$ \\
\hline $\mathrm{CeP}_{\mathrm{pp}}$ & 34 & 32 & 27.9 & 32 & 36 & 44 & $\mathrm{mmHg}$ \\
\hline $\operatorname{ReP}_{\mathrm{pp}}$ & 27 & 25 & 25.2 & 31 & 32 & 30 & $\mathrm{mmHg}$ \\
\hline $\mathrm{CeF}_{\text {mean }}$ & 0.71 & 0.70 & 0.69 & 0.65 & 0.59 & 0.49 & $\mathrm{~L} / \min$ \\
\hline $\mathrm{CoF}_{\text {mean }}$ & 0.22 & 0.22 & 0.22 & 0.20 & 0.17 & 0.13 & $\mathrm{~L} / \min$ \\
\hline $\mathrm{ReF}_{\text {mean }}$ & 1.21 & 1.21 & 1.31 & 1.60 & 2.06 & 2.6 & $\mathrm{~L} / \mathrm{min}$ \\
\hline $\mathrm{SyF}_{\text {mean }}$ & 2.97 & 0.78 & 0.91 & 0.94 & 1.22 & 1.37 & $\mathrm{~L} / \min$ \\
\hline $\mathrm{CO}$ & 5.11 & 2.91 & 3.13 & 3.39 & 4.04 & 4.59 & $\mathrm{~L} / \min$ \\
\hline
\end{tabular}

the systolic from the diastolic pressure at these circulations, rise by $12 \%$ and $30 \%$ respectively.

Figures 9 shows the transient responses of the $\mathrm{CoF}, \mathrm{CeF}, \mathrm{ReF}$ and $\mathrm{CO}$ when the pump is switched on at $3000 \mathrm{rpm}$ and regional autoregulation systems are active. Figure 9 (a) shows that with the pump at $3000 \mathrm{rpm}$ there is no variation in CoF. Figure 9 (b) shows that the CeF drops by $8 \%$ at $\mathrm{T}=12 \mathrm{~s}$, however since CeP remains within the cerebral autoregulated region $(60-120 \mathrm{mmHg})$, the $\mathrm{CeF}$ is autoregulated and returns to the initial steady state level of $0.71 \mathrm{~L} / \mathrm{min}$ at $\mathrm{T}=28 \mathrm{~s}$. It is evident that at $\mathrm{T}=18 \mathrm{~s}$ there is a slight overshoot in the $\mathrm{CeF}$, before reaching the steady state level. Aaslid et al. [36] in a clinical study on humans demonstrated that the $\mathrm{CeF}$ overshoot occurs due to the delay in the autoregulation system compensating for a change in the aortic pressure. Figure 9 (c) shows that the ReF rises by $45 \%$ at $\mathrm{T}=13 \mathrm{~s}$ to $1.65 \mathrm{~L} / \mathrm{min}$, however, since $\mathrm{ReP}_{\text {mean }}$ remains within the renal autoregulated region $(90-180 \mathrm{mmHg})$, the autoregulation system compensates and the CeF returns to the initial level of $1.2 \mathrm{~L} / \mathrm{min}$ by $\mathrm{T}=28 \mathrm{~s}$. Figure 9 (d) shows that with the pump operating at $3000 \mathrm{rpm}, \mathrm{CO}$ gradually increases from $2.9 \mathrm{~L} / \mathrm{min}$ and reaches the steady

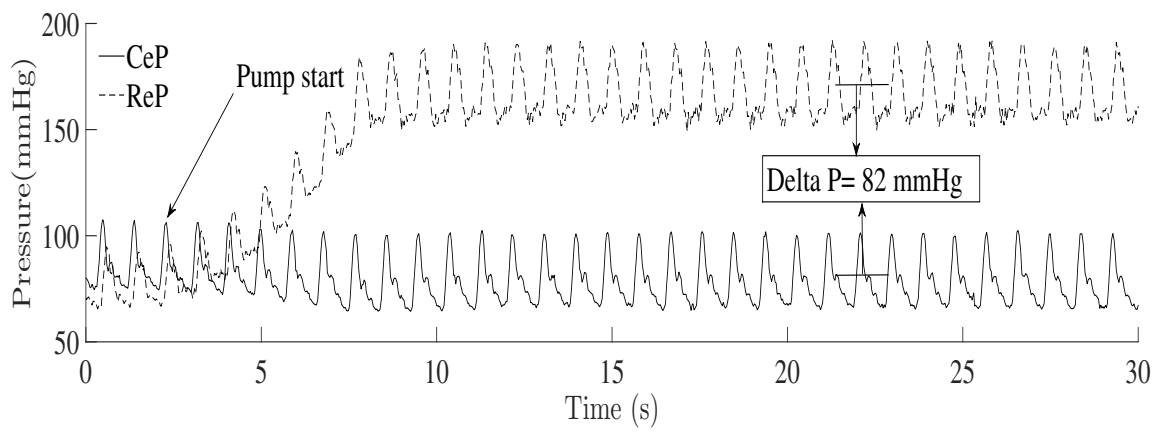

Figure 8: The transient responses of $\mathrm{CeP}$ and ReP with the pump operating at $3000 \mathrm{rpm}$ at $\mathrm{T}=3 \mathrm{~s}$. 


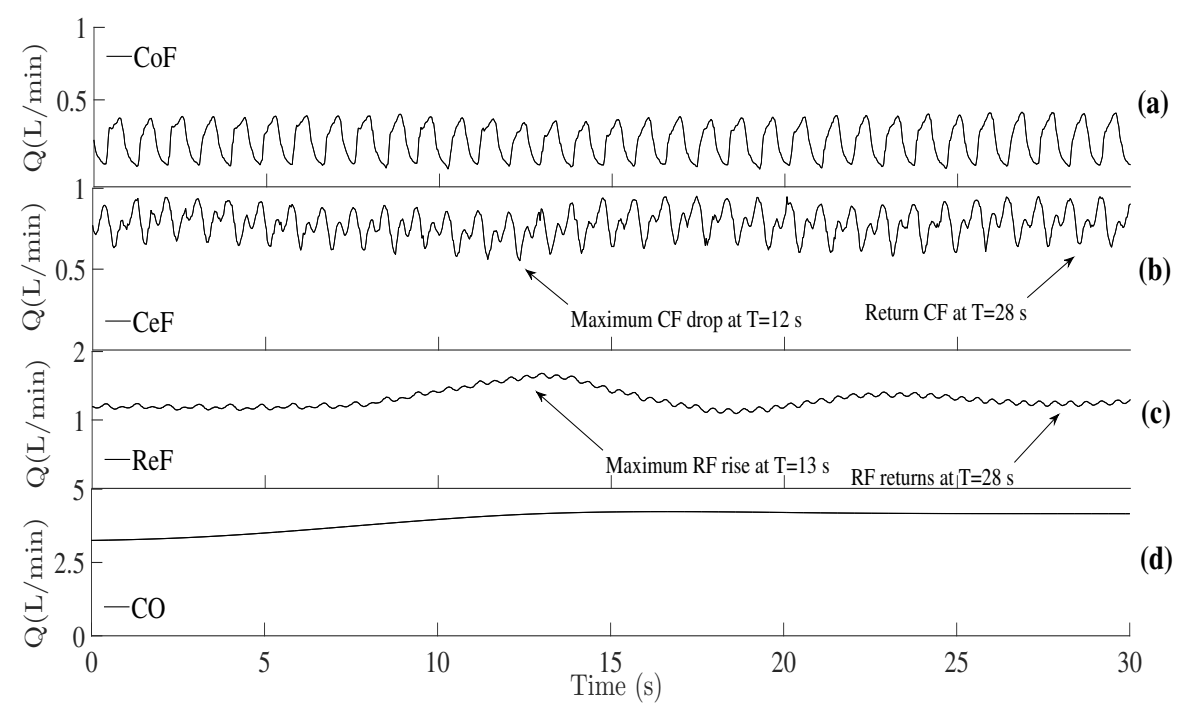

Figure 9: (a) The transient responses of the CoF waveforms (b) CeF waveforms, (c) ReF waveforms, (d) CO with the pump operating at $3000 \mathrm{rpm}$.

level of $4.1 \mathrm{~L} / \mathrm{min}$ over the course of $25 \mathrm{~s}$. The perfusion pressure to the cerebral and coronary circulations remained within the autoregulated regions at all levels of support, so when the autoregulation systems were active there was no drop in $\mathrm{CoF}$ or $\mathrm{CeF}$.

At $4000 \mathrm{rpm}$ AoP mean falls by around $20 \%$. The fall in $\mathrm{AoP}_{\text {mean }}$ can result in reduced perfusion to vital organs when regional autoregulation systems are inactive in this scenario. CeF falls $31 \%$ at $4000 \mathrm{rpm}$, from $0.71 \mathrm{~L} / \mathrm{min}$ to $0.49 \mathrm{~L} / \mathrm{min}$, while CoF falls $41 \%$ from $0.22 \mathrm{~L} / \mathrm{min}$ to $0.13 \mathrm{~L} / \mathrm{min}$. The drop in CoF is larger than the drop in $\mathrm{CeF}$ because of the increased pulsatility; $\mathrm{AoP}_{\text {dia }}$ falls by more than $\mathrm{AoP}_{\text {mean }}$, so the drop in coronary perfusion, which primarily occurs in diastole, is exacerbated. The large pressure increase downstream of the pump causes an increase in renal perfusion. When the autoregulation systems are on, renal flow is unaffected at speeds from 0 to $3000 \mathrm{rpm}$, however at $4000 \mathrm{rpm}$ there is an increase of $22 \%$. When the autoregulation systems are inactive, the renal flow increases proportional to the pressure.

\section{Discussion}

The SCVL was used to accurately replicate clinical pressure waveforms and flow rates for healthy and HF conditions. The novel parallel configuration of a solenoid valve and narrow tubing ensured the coronary was primarily perfused in diastole, as in the native system. The autoregulation units, when active, successfully maintained clinically accurate flow rates in cerebral, coronary and renal circulations and this technique can be used to simulate arterial constriction and dilation in other parts of the body, such as skeletal muscles or intestines [18]. 
With an integrated RBP, operating over a wide range of rotor speeds in the DA, it was observed that the pressure rise generated downstream of the pump was several times higher than the pressure drop generated upstream of the pump. This is because the resistance in lower extremities was much larger than the resistance between the LV and the pump. As demonstrated in previous studies $[6,12,13,29]$, the pressure drop induced by the pump reduces the afterload pressure and thus improves the CO. It was reported in our previous work [13] that the afterload reduction due to a pump operating in the descending aorta results in a greater ejection with the same LV contractile energy, leading to an improvement in LV performance.

If the comparatively low pressure drop in the aortic arch is replicated in-vivo, it suggests that a beneficial level of support could be applied without significant perfusion drops in cerebral and coronary circulations. With regional autoregulation inactive, a $3000 \mathrm{rpm}$ pump speed resulted in a $42 \%$ increase in CO with drops of $17 \%$ and $23 \%$ in $\mathrm{CeF}$ and $\mathrm{CoF}$. Any regional autoregulation activity would reduce these perfusion drops. The pressure rise downstream of the pump improves perfusion to the kidneys. Studies on HF patients showed that the mortality rate is more closely associated with the worsening of renal function than any other established risk factor such as left ventricular ejection fraction [38]. It is reported the worsening renal function is strongly related to the hemodynamic stability of the renal blood flow [39]. Clinical data on the kidney's response to sustained high pressure in humans could not be obtained although it is noted that the renal circulation has a high upper limit to its autoregulation system, at $180 \mathrm{mmHg}$, which was exceeded in our experiment only at the $4000 \mathrm{rpm}$ level of support.

With the rotary pump operating in series with the heart, it was observed that the flow pulsatility in all circulations was improved. This is in contrast to the traditional LVAD implantation, where increasing the level of pump support attenuates the pulsatility [6]. Clinical studies show that the flow pulsatility has a positive effect on recovery of cerebral, renal, and coronary systems functionality in patients with HF [40-42]. However, the pulsatility also results in a lower $\mathrm{AoP}_{\text {dia }}$ which presents a risk to coronary perfusion. A larger perfusion drop was observed in the coronary circulation than in the cerebral circulation during RBP support in the SCVL with regional autoregulation inactive.

In this paper the response of the SCVL to a rotary pump in the descending aorta with and without regional autoregulation systems is compared. The debate of whether and to what extent autoregulation systems are impaired in HF is still ongoing and there was no clear answer from the authors' literature search. Descending aorta RBP has been investigated in animals [16] and man [8] by Reitan et al.. They found that with their percutaneous catheter-based pump in the descending aorta of calves, no variation in the coronary perfusion was observed. A drop of $15 \%$ in CeF was observed, however in the same study the author emphasized on existing differences between the human and animal cerebral functionality and they predicted that the human cerebral autoregulation system would ensure a sufficient blood supply down to $\mathrm{AoP}_{\text {mean }}$ of $60 \mathrm{mmHg}$. In the study in man, such invasive measurements could not be taken.

No other studies on the regional autoregulation involve in-series RBP device insertion. There are stud- 
ies $[43,44]$ showing clearly that the regional autoregulations, particularly cerebral autoregulation is partially impaired in severe HF. However, other studies [45] claim that many patients with moderate to severe HF condition have a normal regional autoregulation due to the redistribution of the blood flow in the cardiovascular system. In addition, there are studies $[44,46]$ show that, in some cases after the RBP implantation or heart transplantation, the impaired regional autoregulation has been improved, following CO re-establishment. Whether or not regional autoregulation is impaired due to heart failure, this study has indicated that the pressure drop in the upper extremities is relatively low (10-12 mmHg at $3000 \mathrm{rpm}$ ) even without regional autoregulation.

There are many advantages, compared to the existing LVAD in-parallel configuration, that makes this approach worthy of investigation. Implantation in the descending aorta is less invasive and possibly can be performed via a left thoracotomy. As a result, the operation would be less expensive and potentially can be done in district general hospitals. Also, this technique may reduce the chance of stroke. For the in-parallel configuration, the thrombi released from the LVAD outlet graft, can be transported along the blood stream through the ascending aorta toward the brain, thereby increasing the chance of stroke [47]. With a RBP in the descending aorta, thrombi would be directed to the lower extremities rather than upper extremities, thus reducing the chance of stroke. However there are some concerns about the in-series implantation which needs further examination through more in-vitro and in-vivo tests. For instance, the level of support should clearly be limited to avoid excessive pressure drops upstream and rises downstream, otherwise perfusion in the cerebral, coronary, and renal circulations may become more impaired than before implantation.

\section{Limitations}

One limitation of this study is the lack of appropriate clinical data on impairment of regional autoregulation in HF. How these systems are affected during HF is an unresolved question which has significant implications for the suitability of descending aorta RBP support. Consequently, we repeated our experiment with and without regional autoregulation systems active to give a best-case and worst-case scenario for in-series support. While the data used here for cardiovascular parameters were collected from a variety of sources, it was not possible to collect all required data from a single individual and the resulting simulations accurately replicate the cardiovascular system of a typical human adult.

For this study the preload (Frank-Starling mechanism) and afterload (autonomic nervous system) sensitivity of the ventricles were not modelled in the SCVL. Preload and afterload sensitive motors have been implemented into other cardiovascular simulators [25, 26, 28]. Implementation of these features in the SCVL is necessary to give a more comprehensive understanding of the hemodynamic effects of an RBP device in the DA. Theoretically, in a native system pressure rise generated downstream of the pump, would cause a high preload pressure in the right atrium which would lead to further improved cardiac output due to 
the Frank-Starling mechanism. In addition, the pressure drop upstream of the pump, would trigger the autonomic nervous mechanism which consequently would lead to the redistribution of blood toward the upper extremities as a result of increased vasoconstriction in the major arterial system [45]. In this study the effect of a rise in hydrostatic pressure due to the horizontal position of the system was not considered. In a supine position, an increased hydrostatic pressure leads to a rise in preload which consequently improves the cardiac output, provided that the Frank-Starling is intact [18].

Although the previous studies show that the improvement in renal flow may have a positive impact on renal functionality $[39,48,49]$, yet the clinical consequence of an the increased renal pressure observed in this study is not known. An in-vivo study [50] on a dog showed that the incremental increase in renal pressure, directly affects the peritubular capillaries in the kidneys and that leads to a rise in urine flow and subsequently urinary sodium excretion. In-vivo tests are mandated in order to evaluate the effect of the pressure rise and extra renal perfusion on kidney functionality.

\section{Conclusions}

This study showed the use of a novel coronary mechanism and autoregulation units in the SCVL. The improved SCVL system is able to emulate the behaviour of the heart during healthy and HF conditions in close agreement to the existing clinical data and allows measurement of pressure and flow in cerebral, coronary and renal circulations. Certainly, having more clinical data, for instance on impairment of the regional autoregulation, would improve the results. The perfusion in these regional circulations may be affected by an RBP device operating in the descending aorta. The extent of changes in perfusion is determined by the level of support and the efficacy of the regional autoregulation systems. Our work suggests that a beneficial level of support is possible at $3000 \mathrm{rpm}$ without detrimental effects on the cerebral and coronary perfusion, but only with unimpaired regional autoregulation. In a future study, we will replicate impaired cerebral, coronary and renal autoregulaton in the SCVL once suitable clinical data has been obtained. It is our intention to integrate the autonomic and Frank-Starling mechanisms to the SCVL system and investigate the hemodynamic responses of the whole system in detail with an RBP operating in the descending aorta.

\section{Conflict of interest statement}

None.

\section{Acknowledgments}

This report is independent research funded by the National Institute for Health Research [i4i, Turbocardia, II-LB-1111-20007]. Principal Investigator for the grant is Prof. T. Korakianitis. The views expressed 
in this publication are those of the authors and not necessarily those of the NHS, the National Institute for Health Research or the Department of Health.

\section{References}

[1] Dariush Mozaffarian, Emelia J. Benjamin, Alan S Go, and et al. Executive summary: Heart disease and stroke statistics2015 update a report from the american heart association. Circulation, 131(4):434-441, JAN 272015.

[2] Lars H. Lund, Leah B. Edwards, Anna Y Kucheryavaya, and et al. The registry of the international society for heart and lung transplantation: Thirty-first official adult heart transplant report-2014; focus theme: Retransplantation. Journal of Heart and Lung Transplantation, 33(10):996-1008, OCT 2014.

[3] Eric D. Adler, Judith Z. Goldfinger, Jill Kalman, Michelle E. Park, and Diane E. Meier. Palliative care in the treatment of advanced heart failure. Circulation, 120(25):2597-2606, DEC 222009.

[4] B. P. Griffith, R. L. Kormos, H. S. Borovetz, K. Litwak, J. F. Antaki, V. L. Poirier, and K. C. Butler. Heartmate ii left ventricular assist system: From concept to first clinical use. Annals of Thoracic Surgery, 71(3S):116-120, March 2001.

[5] C. Christiansen, A. Klocke, and R Autschbach. Past, present, and future of long-term mechanical cardiac support in adults. Journal of Cardiac Surgery, 23(6):664-676, Dec 2008.

[6] M. A. Rezaienia, A. Rahideh, M. T. Rothman, S. A. Sell, K. Mitchell, and T. Korakianitis. In vitro comparison of two different mechanical circulatory support devices installed in series and in parallel. Artificial Organs, 38(9):800-809, 2014.

[7] J.D. Schmitto, S.V. Rojas, J.S. Hanke, M. Avsar, and A. Haverich. Minimally invasive left ventricular assist device explantation after cardiac recovery: surgical technical considerations. Artificial Organs, 38(6):507-10, June 2014.

[8] E. J. Smith, O. Reitan, T. Keeble, K. Dixon, and M. T. Rothman. A first-in-man study of the reitan catheter pump for circulatory support in patients undergoing high-risk percutaneous coronary intervention. Catheterization and Cardiovascular Interventions, 73(7):859-865, June 2009.

[9] E. Okamoto, T. Yano, Y. Shiraishi, H. Miura, T. Yambe, and Y. Mitamura. Initial acute animal experiment using a new miniature axial flow pump in series with the natural heart. Artificial Organs, 39(8):701-728, 2016.

[10] J. N. Bhayana, S. M. Scott, G. K. Sethi, and Takaro. T. Effects of intra-aortic balloon pumping on organ perfusion in cardiogenic shock. Journal of Surgical Research, 26(2):108113, 1979.

[11] Theodosios Korakianitis, Mohammad A. Rezaienia, Gordon M. Paul, Akbar Rahideh, Martin T. Rothman, and Sahand Mozafari. Optimization of Centrifugal Pump Characteristic Dimensions for Mechanical Circulatory Support Devices. ASAIO Journal, page In Press, 2016.

[12] P. Ruiz, M. A. Rezaienia, A. Rahideh, T. R. Keeble, M. T. Rothman, and T. Korakianitis. In vitro cardiovascular system emulator (bioreactor) for the simulation of normal and diseased conditions with and without mechanical circulatory support. Artificial Organs, 37(6):549-560, Jun 2013.

[13] M. A. Rezaienia, A. Rahideh, B. A. Hamedani, D.E.M. Bosak, S. Zustiac, and T. Korakianitis. Numerical and in vitro investigation of a novel mechanical circulatory support device installed in the descending aorta. Artificial Organs, 39(6):502-513, June 2015.

[14] C. del Rio, W. Clifton, J. Heuring, B. Hertzog, Y. Ueyama, B. Youngblood, and P.I. McConnell. Aortix, a novel catheterbased intra-vascular assist device, provides cardio-renal support while improving ventriculo-arterial coupling and myocardial demand in sheep with induced chronic ischemic heart failure. Journal of the American College of Cardiology, 65(10), March 2015.

[15] Y. Wang, P. L. Hsu, H. C. Love, D. L. Timms, and R. A. McMahon. In vitro study of an intra-aortic vad: Effect of reverse-rotating mode on ventricular recovery. In 37th Annual International Conference of the IEEE Engineering in Medicine and Biology Society (EMBC), pages 274-277. IEEE, 2015. 
[16] O. Reitan, S. Steen, and H. Ohlin. Hemodynamic effects of a new percutaneous circulatory support device in a left ventricular failure model. ASAIO Journal, 49(6):731-736, 2003.

[17] L.G. Bongartz, M.J. Cramer, P.A. Doevendans, J.A. Joles, and B. Braam. The severe cardiorenal syndrome: "guyton revisited". European Heart Journal, 26(1):11-17, 2005.

[18] A.C. Guyton. Textbook of Medical Physiology. W.B. Saunders Company, 1986.

[19] L.C. Mchenry, J.W. West, E.S. Cooper, H.I. Goldberg, and M.E. Jaffe. Cerebral autoregulation in man. Stroke, 5(6):695706,1974 .

[20] O.B. Paulson, S. Strandgaard, and L. Edvinsson. Cerebral autoregulation. Cerebrovascular and Brain Metabolism Reviews, 2(2):161-192, 1990.

[21] N.H.J. Pijls and B. De Bruyne. Coronary Pressure. Springer, 2013.

[22] J.M. Marsh and Holstein N.H. Renal blood flow regulation and arterial pressure fluctuations : A case study in nonlinear dynamics. Physiological Reviews, 74(3), 1994.

[23] B. Braam, W.A. Cupples, J.A. Joles, and C. Gaillard. Systemic arterial and venous determinants of renal hemodynamics in congestive heart failure. Heart Failure Reviews, 17(2):161-175, 2012.

[24] S. Strandgaard. Autoregulation of cerebral blood-flow in hypertensive patients - modifying influence of prolonged antihypertensive treatment on tolerance to acute, drug-induced hypotension. Circulation, 53(4):720-727, 1976.

[25] J.R. Crosby, K.J. DeCook, P.L. Tran, R.G. Smith, D.F. Larson, Z.I. Khalpey, D. Burkhoff, and M.J. Slepian. Physiological characterization of the syncardia total artificial heart in a mock circulation system. ASAIO Journal, 61(3):274-281, May 2015 .

[26] S.D. Gregory, M. Stevens, D. Timms, and M. Pearcy. Replication of the frank-starling response in a mock circulation loop. In 2011 International Conference of the IEEE Engineering in Medicine and Biology Society (EMBC), pages 6825-6828. IEEE, 2011.

[27] G. M. Pantalos, C. Ionan, S. C. Koenig, K. J. Gillars, T. Horrell, S. Sahetya, J. Colyer, and L. A. Gray. Expanded pediatric cardiovascular simulator for research and training. ASAIO Journal, 56(1):67-72, 2010.

[28] S.H. Jansen-Park, M.N. Mahmood, I. Müller, L.K. Turnhoff, T. Schmitz-Rode, U. Steinseifer, and S.J. Sonntag. Effects of Interaction Between Ventricular Assist Device Assistance and Autoregulated Mock Circulation Including Frank-Starling Mechanism and Baroreflex. Artificial Organs, Accepted November 20152015.

[29] M. A. Rezaienia, P Gordon, E. Avital, A. Rahideh, M. T. Rothman, and T. Korakianitis. In-vitro investigation of cerebral-perfusion effects of a rotary blood pump installed in the descending aorta. Journal of Biomechanics, 49(9):1-8, 2016.

[30] A. C. Guyton and J. E. Hall. Textbook of Medical Physiology. Elsevier Saunders, 2006.

[31] B.F. Palmer. Renal dysfunction complicating the treatment of hypertension. New England Journal of Medicine, 347(16):1256-1261, 2002.

[32] E. I. Cabrera Fischer, R. L. Armentano, F. M. Pessana, S. Graf, L. Romero, A. I. Christen, A. Simon, and J. Levenson. Endothelium-dependent arterial wall tone elasticity modulated by blood viscosity. American Journal of Physiology-Heart and Circulatory Physiology, 282(2):389-394, 2002.

[33] A.C.W. Lin, A. Lowe, K. Sidhu, W. Harrison, P. Ruygrok, and R. Stewart. Evaluation of a novel sphygmomanometer, which estimates central aortic blood pressure from analysis of brachial artery suprasystolic pressure waves. Journal of Hypertension, 30(9):1743-1750, September 2012.

[34] S. J. Denardo, R. Nandyala, G. L. Freeman, G. L. Pierce, and W. W. Nichols. Pulse wave analysis of the aortic pressure waveform in severe left ventricular systolic dysfunction. Circulation-Heart Failure, 3(1):149-156, 2010.

[35] G. Ferrari, C. D. Lazzari, M. Kozarski, F. Clemente, K. Gorczynska, R. Mimmo, E. Monnanni, G. Tosti, and M. Guaragno. A hybrid mock circulatory system: Testing a prototype under physiologic and pathological conditions. ASAIO Journal, 
48(5):487-494, 2002.

[36] A. Rune, K.F. Lindegaard, W. Sorteberg, and H. Nornes. Cerebral autoregulation dynamics in humans. Stroke, 56(36):45$53,1989$.

[37] M.D. Ford, N. Alperin, S.H. Lee, D.W. Holdsworth, and D.A. Steinman. Characterization of volumetric flow rate waveforms in the normal internal carotid and vertebral arteries. Physiological Measurement, 26(4):477-488, August 2005.

[38] R. E. Schmieder, V. Mitrovic, and C. Hengstenberg. Renal impairment and worsening of renal function in acute heart failure: can new therapies help? the potential role of serelaxin. Clinical Research in Cardiology, 104(8):621-631, March 2015.

[39] T. D. J. Smilde, K. Damman, P. Van der Harst, G. Navis, B. Daan Westenbrink, A. Voors, and H. L. Hillege. Differential associations between renal function and modifiable risk factors in patients with chronic heart failure. Clinical Research in Cardiology: Official Journal of the German Cardiac Society, 98(2):121-129, 2009.

[40] H. K. Kim, H. S. Son, Y. H. Fang, S. Y. Park, C. M. Hwang, and K. Sun. The effects of pulsatile flow upon renal tissue perfusion during cardiopulmonary bypass: A comparative study of pulsatile and nonpulsatile flow. ASAIO Journal, 51(1):30-36, January 2005.

[41] A. Undar. Myths and truths of pulsatile and nonpulsatile perfusion during acute and chronic cardiac support. Artificial Organs, 28(5):439-443, May 2004.

[42] A. Sezai, M. Shiono, Y. Orime, K. Nakata, M. Hata, M. Iida, S. Kashiwazaki, J. Kinoshita, M. Nemoto, T. Koujima, M. Furuichi, K. Eda, H. Hirose, T. Yoshino, A. Saitoh, T. Taniguchi, and Y. Sezai. Major organ function under mechanical support: Comparative studies of pulsatile and nonpulsatile circulation. Artificial Organs, 23(3):280-285, March 1999.

[43] M. Saha, M.R. Muppala, J.E. Castaldo, W. Gee, J.F. Reed, and D.L. Morris. The impact of cardiac index on cerebral hemodynamics. Stroke: A journal of cerebral circulation, 24(11):1686-1690, 1993.

[44] N. Gruhn, F.S. Larsen, S. Boesgaard, G.M. Knudsen, S. Mortensen, G. Thomsen, and J. Aldershvile. Cerebral blood flow in patients with chronic heart failure before and after heart transplantation. Stroke: A journal of cerebral circulation, 32(11):2530-2533, 2001.

[45] H. Rappaport, D. Bruce, and T Langfitt. The effect of lowered cardiac output on cerebral blood flow. Cerebral circulation and metabolism, 4:14-17, 1975.

[46] William K. Cornwell and Benjamin D. Levine. Patients with heart failure with reducedejection fraction have exaggerated reductions in cerebral blood flow during upright posture. Heart Failure, 3(2):176-179, 2015.

[47] MJ Wilhelm, D Hammel, C Schmid, A Rhode, T Kaan, M Rothenburger, J Stypmann, M Schafers, C Schmidt, HA Baba, and HH Scheld. Long-term support of 9 patients with the debakey vad for more than 200 days. Journal of Thoracic and Cardiovascular Surgery, 130(4):1122-1129, OCT 2005.

[48] M. Metra, G. Cotter, M. Gheorghiade, C.L. Dei, and A.A. Voors. The role of he kidney in heart failure. Eur Heart J, $3(17): 2135-2142,2012$.

[49] H.L. Hillege, A.R. Girbes, P.J. Kam, F. Boomsma, D. Zeeuw, A. Charlesworth, J.R. Hampton, and D.J. Veldhuisen. Renal function, neurohormonal activation, and survival in patients with chronic heart failure. Circulation, 102(2):203210, 2000.

[50] C. Aperia, C. G. Ove Broberger, and P. Surgery. Relationship and tubular between sodium renal artery perfusion pressure reabsorption. American Journal of Physiology, 220(5):1205-1212, 1971. 